This is the peer-reviewed version of the following article: Mori M, Vignaroli G, Cau Y, et al. Discovery of 14-3-3 protein-protein interaction inhibitors that sensitize multidrug-resistant cancer cells to doxorubicin and the Akt inhibitor

GSK690693. ChemMedChem. 2014;9(5):973-983. doi:10.1002/

cmdc.201400044, which has been published in final form at https://

doi.org/10.1002/cmdc.201400044. This article may be used for noncommercial purposes in accordance with Wiley-VCH Terms and Conditions for Self-Archiving.

All Rights

Reserved

(C) 2014 WILEY-VCH Verlag GmbH \& Co. KGaA, Weinheim. 


\section{Discovery of 14-3-3 Protein-Protein Interaction Inhibitors that Sensitize Multidrug-Resistant Cancer Cells to Doxorubicin and the Akt Inhibitor GSK690693}

Mattia Mori $^{+a, b}$, Giulia Vignaroli ${ }^{+}$a, Ylenia $\mathrm{Cau}^{\mathrm{a}}$, Jelena Dinićc ${ }^{\mathrm{c}}$, Richard Hill ${ }^{\mathrm{de}}$, Matteo Rossi $^{\mathrm{a}, \mathrm{f}}$, David Colecchia ${ }^{\mathrm{f}, \mathrm{g}}$, Milica Pešićc ${ }^{\mathrm{c}}$, Wolfgang Link ${ }^{\mathrm{d}, \mathrm{e}}$, Mario Chiariello ${ }^{\mathrm{f,g}}$, Christian Ottmann $^{\mathrm{h}}$, Maurizio Botta ${ }^{*, \mathrm{a}, \mathrm{i}}$

${ }^{a}$ Dipartimento di Biotecnologie, Chimica e Farmacia, Università degli Studi di Siena, Via Aldo Moro 2, 53100 Siena (Italy)

${ }^{\mathrm{b}}$ Center for Life Nano Science@Sapienza, Istituto Italiano di Tecnologia, Viale Regina Elena 291, 00161 Roma (Italy)

" Institute for Biological Research "Siniša Stanković", Department of Neurobiology, University of Belgrade, Despota Stefana 142, 11060 Belgrade (Serbia)

${ }^{\mathrm{d}}$ Regenerative Medicine Program, Departamento de Ciências Biomédicas e Medicina, Universidade do Algarve, Campus de Gambelas, 8005-139 Faro (Portugal)

${ }^{\mathrm{e}}$ IBB - Institute for Biotechnology and Bioengineering, Centro de Biomedicina Molecular e Estrutural, Universidade do Algarve, Campus de Gambelas, Faro (Portugal)

${ }^{\mathrm{f}}$ Core Research Laboratory, Istituto Toscano Tumori, Via Fiorentina 1, 53100 Siena (Italy)

${ }^{g}$ Istituto di Fisiologia Clinica, Consiglio Nazionale delle Ricerche, Sede di Siena, Via Fiorentina 1, 53100 Siena (Italy)

${ }^{\mathrm{h}}$ Department of Biomedical Engineering, Technische Universiteit Eindhoven, P.O. Box 513, $5600 \mathrm{MB}$ Eindhoven (The Netherlands)

${ }^{\mathrm{i}}$ Sbarro Institute for Cancer Research \& Molecular Medicine, Center for Biotechnology, College of Science \& Technology, Temple University, BioLife Science Building, Suite 333, 1900 North 12th Street, Philadelphia, PA 19122 (USA)

* Corresponding Author: Prof. Maurizio Botta; E-mail address: botta.maurizio@gmail.com

+ These authors contributed equally to this work 


\begin{abstract}
14-3-3 is a family of highly conserved adapter proteins that is attracting much interest among medicinal chemists. Small-molecule inhibitors of 14-3-3 protein-protein interactions (PPIs) are in high demand, both as tools to increase our understanding of 14-3-3 actions in human diseases and as leads to develop innovative therapeutic agents. Herein we present the discovery of novel 14-3-3 PPI inhibitors through a multidisciplinary strategy combining molecular modeling, organic synthesis, image-based high-content analysis of reporter cells, and in vitro assays using cancer cells. Notably, the two most active compounds promoted the translocation of c-Abl and FOXO pro-apoptotic factors into the nucleus and sensitized multidrug-resistant cancer cells to apoptotic inducers such as doxorubicin and the pan-Akt inhibitor GSK690693, thus becoming valuable lead candidates for further optimization. Our results emphasize the possible role of 14-3-3 PPI inhibitors in anticancer combination therapies.
\end{abstract}

Keywords: antitumor agents; cancer; doxorubicin; inhibitors; multidrug resistance; proteinprotein interactions 


\section{Introduction}

14-3-3 is a family of adapter proteins highly involved in eukaryotic cellular signaling, cell cycle regulation, protein trafficking, metabolism, and control of apoptosis [1]. Seven 14-3-3 isoforms have been isolated and characterized, carrying out their functions by establishing protein-protein interactions (PPIs) with a plethora of different cellular partners that generally present a phosphorylated 14-3-3 binding site [2]. 14-3-3 proteins function as homo- or heterodimers, with each monomer displaying the so named amphipathic groove where the binding to phosphorylated 14-3-3 partners takes place. Structural determinants involved in 14-3-3 PPIs have been deeply investigated and reviewed by our and other research groups [2a, 3].

More than 500 cellular partners of 14-3-3 have been identified and classified by bioinformatic and proteomic studies [4]. Among them, several proteins raised much interest in drug discovery, such as c-Abl and Raf kinases, p53, MLF1, FOXO transcription factors, Cdc25, $\mathrm{Bad}$, and Tau, thus highlighting the potential of 14-3-3 as a family of target proteins for the development of small-molecule PPI inhibitors of pharmacological relevance [3a, 5].

From a pathological standpoint, 14-3-3 has been implicated in many different human diseases, probably as a consequence of the extensive PPIs established inside the eukaryotic cell. Particularly, the involvement of 14-3-3 in neurodegenerative disorders such as CreutzfeldtJacob [6], Alzheimer's, and Parkinson's diseases [6a, 7], in the virulence of pathogens in humans [8], and in the regulation of metabolism [9] and cardiac functions [6b] has been reported. Several works have reported on the clear involvement of 14-3-3 in cancer [10], even though their role seem to be rather tissue-specific and, in a few cases, the cancer promotion/inhibitory activity of 14-3-3 is still matter of debate [11]. Of particular interest for medicinal chemistry approaches is the case of 14-3-3 $\sigma$. In addition to playing a critical role in the cytoplasmic compartmentalization of pro-apoptotic and anti-proliferative proteins through PPIs in chronic myeloid leukemia (CML) and hematological malignancies [12], it has been identified as a major contributor to drug resistance in cancer cells [13]. Accordingly, the development of small-molecule inhibitors of 14-3-3 $\sigma$ PPIs may have a significant impact on the growth of normal, as well as drug-resistant, cancer cells. Moreover, these molecules may provide biologists and pharmacologists with a unique tool for progressing toward the validation of 14-3-3 proteins as targets for anticancer therapy and may represent valuable starting points for the development of promising lead candidates.

In recent years, a number of small-molecule modulators of 14-3-3 PPIs have been discovered and characterized [3a,5]. Of particular interest are natural products and small molecules as stabilizers of 14-3-3 PPIs, which have been characterized by means of high-throughput screening and X-ray crystallography [5a, 14]. Moreover, in 2010, Wu and co-workers discovered a phosphorylated peptide mimetic by means of microarray-assisted screening as the first small-molecule inhibitor of 14-3-3 PPI [15]. In a recent attempt to obtain 14-3-3 PPI inhibitors, we reported the discovery and biological characterization of BV02 as the first nonpeptidic or peptidomimetic small molecule inhibiting 14-3-3б/c-Abl PPI in vitro and restoring c-Abl nuclear levels, thus promoting apoptosis and inducing an anti-proliferative effect in CML cancer cells [16]. Furthermore, we demonstrated that BV02 was also able to inhibit 14- 
3-3 PPIs on hematopoietic cells expressing the imatinib-sensitive wild-type Bcr-Abl and the imatinib-resistant T315I mutation [12a]. However, further studies revealed that BV02 undergoes spontaneous chemical cyclization at room temperature, seriously impairing the characterization of the bioactive form. To overcome this issue, we developed an additional 14-3-3 PPI inhibitor, BV01, which has anti-proliferative activity in vitro at low micromolar

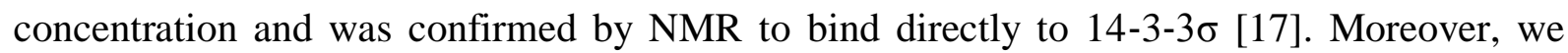
have optimized a high-throughput cellular imaging assay that monitors nuclear/cytoplasmic compartmentalization and translocation of a fluorescent GPF-FOXO3A fusion protein in tumor cells, which is a valuable tool to effectively screen 14-3-3 PPI inhibitors in vitro [18].

Here, with the aim of providing 14-3-3 PPI inhibitors with improved potency as lead candidates for anticancer therapy and affording structure-activity relationships (SAR) for this class of molecules, we generated and screened in silico a focused library of compounds based on BV01 and BV02. Virtual hits were then synthesized and tested in vitro by the FOXO translocation assay. The most potent 14-3-3 PPI inhibitors identified herein were also able to promote $\mathrm{c}-\mathrm{Abl}$ translocation into the nucleus, thus restoring pro-apoptotic stimuli, presumably

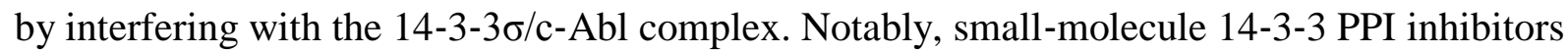
significantly sensitized multidrug-resistant (MDR) cancer cells to the chemotherapeutic agent doxorubicin and the pan-Akt inhibitor GSK690693, thus highlighting the promising role of 14-3-3 PPI inhibitors as modulators of apoptosis in anticancer combination therapies. Results of this integrated medicinal chemistry study corroborate the validity of our computational approach and provide small-molecule 14-3-3 PPI inhibitors as tools to investigate the functions of this protein family in MDR cancers as well as to develop medicinally active agents.

\section{Results and Discussion}

\section{Design and virtual screening of the focused library}

Most of the promising 14-3-3 PPI inhibitors discovered by our research group in previous works consist of a negative ionizable "head" connected to a lipophilic "tail" by an amino or amino derivative linker. These were designed with the aim of interacting within the amphipathic groove of 14-3-3, which is the binding site for 14-3-3 phosphorylated partner proteins. Specifically, the tail portion of 14-3-3 PPI inhibitors is aimed to interact within the hydrophobic region of the amphipathic groove, consisting of Phe 119, Pro 167, Ile 168, Leu 174, Ile 219, and Leu 222. In contrast, the head of the scaffold is thought to interact within the polar region of the amphipathic groove characterized by the cluster of basic residues Lys 49, Arg 56, Arg 60, and Arg 129 and by Tyr 130, Asn 175, and Asn 226, which are also contacted by the phosphorylated partners of 14-3-3 (residue numbers are taken from

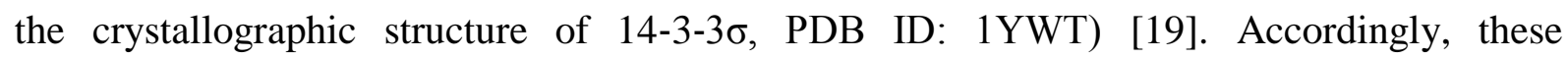
molecules are thought to inhibit 14-3-3 PPIs by binding directly to 14-3-3, as confirmed by previous NMR studies [17].

With the aims of providing lead candidates characterized by enhanced activity and affording SAR that may be useful for improving ligand binding affinity to 14-3-3, we generated a 
focused virtual library of compounds in silico by combining 400 different heads with eight different tails by means of a custom script in Python language, based on the OpenEye OEChem Python Toolkit for library generation (OELibraryGen) [20]. When generating the virtual library, the synthetic feasibility of the compounds was taken into account to allow straightforward and accessible synthesis of the most promising virtual hits. Particularly, to connect the "head" and the "tail" portions of the scaffold, the amide and amine linkers of BV02 and BV01, respectively, were used in addition to the ureido and enamide groups. Heads bearing at least a polar group (i.e., negative ionizable functionality, hydrogen bond acceptor) were selected; tails chosen were simple modifications of those characterizing the previously identified hits BV01 and BV02. Furthermore, taking into account the chemical instability experienced with BV02, its closed phthalimidic analogue was also included into the virtual library (see below for details).

Molecules of the library were then docked toward the crystallographic structure of the 14-3$3 \sigma$ (PDB ID: 1YWT) [19] using the same virtual screening protocol previously described $[12 \mathrm{a}, 16,17]$. Ten virtual hits were selected (Figure 1) based on their binding modes and scoring values, then the compounds were synthesized and submitted to biological tests.

\section{FOXO translocation assay to test 14-3-3 PPI inhibitors}

Virtual hits were synthesized, purified, and characterized as described below. The ten molecules prioritized by virtual screening were tested as putative 14-3-3 PPI inhibitors for their ability to release FOXO3A from 14-3-3-mediated cytoplasmic sequestration [21]. FOXO3A translocation was monitored by the U2foxRELOC assay [18b, 22]. Compounds that induced a nuclear accumulation of the fluorescent signal greater than $60 \%$ of that obtained from wells treated with the PI3K inhibitor LY294002 were considered hits. To assess the cytotoxicity of our compounds, we monitored several additional parameters in a multiplexed manner [23]. In particular, we monitored nuclear shrinkage known to be associated with cell death by analyzing nucleus size, shape, and staining intensity, as well as the number of nuclear vertices. The term nuclear vertices refers to the number of pixels that lie on the nuclear boundary [24]. Among the tested molecules, 8, 9, and $\mathbf{1 0}$ induced the nuclear accumulation of FOXO reporter proteins. Molecules 1 and 3-7 showed moderate activity, while 2 was considered inactive. DMSO $1 \%$ was used as a negative control. None of the tested molecules exhibited any significant cytotoxic effects measured using the abovementioned parameters (Figure 2).

\section{Predicted binding mode and SAR of the most potent 14-3-3 PPI inhibitors}

Molecular docking studies were performed to predict the ligand binding mode within the

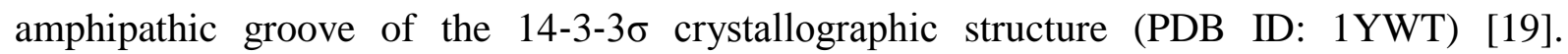
Molecular modeling predictions, coupled with results of the FOXO translocation assay, allowed the identification of rough SAR.

All of the selected molecules shown in Figure 1 bind within the cluster of basic residues consisting of Lys 49, Arg 56, Arg 60, and Arg 129, also showing a fine overlap with the crystallographic pose of 14-3-3 phosphorylated partners [3a]. The most potent derivatives, 8 , 
9, and 10, share the 4-aminoantipyrine tail, which is hydrogen bonded to the side chain of Lys 122 and Asn 175 and forms hydrophobic interactions with Phe 119, Pro 167, Ile 168, Ile 219, and Leu 222 (Figure 3). The ureido linker of $\mathbf{8}$ and $\mathbf{1 0}$ performs additional hydrogen bond interactions with the side chain of Asn 175. With respect to the polar head, 8, 9, and $\mathbf{1 0}$ interact with the abovementioned cluster of basic residues and with the side chain of Tyr 130 . Unlike 9, compounds $\mathbf{8}$ and $\mathbf{1 0}$ bear an additional hydrogen bond acceptor group substitution at the meta position that interacts with Asn 226 (Figure $3 \mathrm{~A}, \mathrm{C}$ ).

Analysis of moderately active and inactive compounds (1-7) further suggests that lipophilic tails bearing alkyl chains and aromatic rings $(\mathbf{2}, \mathbf{3}$ and $\mathbf{5})$, as well as small modifications of the 4-aminoantipyrine (4 and 6), perform worse than the 4-aminoantipyrine itself. Derivatives 16, which are characterized by an amino or amide linker between the head and the tail, showed moderate or no activity, thus suggesting that the ureido group may be the ideal linker in terms of dimension and electronic properties. With respect to the aromatic ring common to all polar heads, a single nitro group at the meta position ( 6 and 7) seems to be insufficient to provide high potency of action, as does the carboxyl group substituted at the para position (1 and $\mathbf{2}$ ).

Finally, as docking results did not provide structural hints to understand the potency of $\mathbf{8}$ being weaker than that of $\mathbf{1 0}$ in the cell-based assay, we speculated that the two carboxyl functionalities of $\mathbf{8}$ negatively impact its ability to cross the biological membranes, as also suggested by $\log P$ and cell permeability predictions in silico (Table S2, Supporting Information). For this reason, $\mathbf{9}$ and $\mathbf{1 0}$ were further investigated in vitro.

\section{Chemical synthesis of virtual hits}

For the sake of clarity, only the synthesis of the two most active 14-3-3 PPI inhibitors 9 and $\mathbf{1 0}$ are described herein, while the synthesis of other virtual hits is available in the Supporting Information. BV02 has been characterized as the first non-peptidic or peptidomimetic 14-3-3 PPI inhibitor [16]. However, we noticed that it underwent spontaneous cyclization at room temperature, producing the opened 2-carbamoyl benzoic derivative in equilibrium with its closed phthalimide form, as reported in Scheme 1 [17], thus limiting the identification of the chemical structure responsible for the observed biological activity. HPLC and LC-MS analyses clearly confirmed the presence of both species in solution (see Supporting Information for details).

As anticipated, we decided to introduce a close derivative of BV02 into the virtual library, namely 9, which was selected by the virtual screening protocol as a putative 14-3-3 PPI inhibitor. Accordingly, 9 was synthesized as summarized in Scheme 2 and submitted to biological tests. Starting from trimellitic anhydride (11) and 4-aminoantipyrine (12), using DMAP as a base and DMF as solvent, the desired product (9) was obtained as a white precipitate after $12 \mathrm{~h}$ at $110^{\circ} \mathrm{C}$ by adding water to the reaction mixture [25]. HPLC, mass spectra, and NMR analyses confirmed the structure and high purity ( $>98 \%)$ of 9 . To check the chemical stability of $\mathbf{9}$ at physiological conditions, we performed preliminary pH-based NMR studies by solubilizing the compound in $125 \mathrm{mM}$ phosphate buffer, $\mathrm{pH} 7.4, \mathrm{D}_{2} \mathrm{O}$, and $\left[\mathrm{D}_{6}\right] \mathrm{DMSO}$. These studies suggested that the closed-ring form is stable in a $\mathrm{pH}$ range between 
7.0 and 8.0, which included the physiological $\mathrm{pH} 7.4$ (experiments were conducted at $\mathrm{pH} 7.2$, 7.4, and 8.0; see Supporting Information for details).

Compound 10, selected by the virtual screening protocol as a potential 14-3-3 PPI inhibitor, is characterized by an ureido group as the linker between head and tail. To perform its synthesis, a classical approach of condensation between the isocyanate and amine moieties was applied [26]. Starting from dimethyl 5-isocyanatoisophthalate (13) and 4-aminoantipyrine (12) in dichloromethane at room temperature, $\mathbf{1 0}$ was obtained as a white precipitate and recovered from the reaction mixture by vacuum filtration (Scheme 3). HPLC, MS, and NMR analyses confirmed the structure and high purity $(>98 \%)$ of $\mathbf{1 0}$.

\section{Effect of 9 and 10 on the nuclear translocation of c-Abl}

c-Abl nuclear translocation upon treatment with $\mathbf{9}$ and $\mathbf{1 0}$ was assessed using HeLa adenocarcinoma cells stably overexpressing EGFP-tagged c-Abl (HeLa EGFP-Abl) as a reporter system. Confocal microscopy images of HeLa EGFP-Abl cells clearly show an increase in nuclear EGFP-Abl in the presence of $\mathbf{9}$ and 10, relative to the negative control (Figure 4 A-C). Next, the extent of the effect of both $\mathbf{9}$ and $\mathbf{1 0}$ on EGFP-Abl subcellular localization was quantitatively scored by analyzing the confocal microscopy images with Volocity software (PerkinElmer Life Science), confirming the ability of both $\mathbf{9}$ and $\mathbf{1 0}$ to promote nuclear re-localization of c-Abl (Figure $4 \mathrm{D}$ ). Treatment with $\mathbf{1 0}$ proved especially effective, leading to significant differences in EGFP-Abl subcellular localization at a concentration as low as $10 \mu \mathrm{M}$. Interestingly, no further increase was observed in EGFP-Abl at higher doses. In fact, upon treatment, the high levels of overexpressed EGFP-Abl might saturate the apparatus responsible of such active nuclear-cytoplasmic shuttling, thus reaching a plateau and preventing the detection of further increases in nuclear fluorescence. Hence, our molecules were able to promote maximum levels of nuclear translocation, even in an experimental setting in which Abl is overexpressed. This result further underscores the efficacy of our molecules, strongly suggesting that similar doses might be largely effective on the endogenous protein.

\section{Activity of 9 and 10 in MDR cancer cells}

14-3-3 PPI inhibitors were tested for their specific anticancer activity in MDR cancer cell lines and their drug-sensitive counterparts. To that end, we employed human non-small-cell lung carcinoma cell lines (sensitive NCI-H460 and MDR NCI-H460/R), as well as colon carcinoma cell lines (sensitive DLD1 and MDR DLD1-TxR). Both 9 and 10 exerted moderate cell growth inhibitory effects in NCI-H460 (Figure 5 A) and NCI-H460/R cells (Figure 5 B). The addition of compounds 9 or 10 (each at $10 \mu \mathrm{M}$ ) to doxorubicin (DOX) improved the effect of DOX in both NCI-H460 (Figure 5 C, D) and NCI-H460/R cells (Figure 5 E, F). Notably, a significant improvement in DOX efficacy, illustrated as a decrease in its $\mathrm{IC}_{50}$ value, was observed in MDR cells (Figure 5 F). Synergism with DOX, as analyzed by CalcuSyn software (Supporting Information), was accompanied by an increase in DOX accumulation in MDR cells (Figure $5 \mathrm{G}$ ). The most prominent effects were observed for $\mathbf{1 0}$ (Figure $5 \mathrm{E}-\mathrm{G}$ ). 
To determine whether DOX accumulation was related to modulation of P-glycoprotein, a membrane efflux pump involved in drug resistance, we monitored the effect of our 14-3-3 PPI inhibitors, as well as the pan-Akt inhibitor GSK690693, on P-glycoprotein expression in DLD-TxR cells. Notably, 9 and $\mathbf{1 0}$ provided a decrease in P-glycoprotein expression compared with that of GSK690693 (Figure 6 A-D). Moreover, considering that GSK690693 treatment increases FOXO1A and FOXO3A transcriptional activity and induces apoptosis [27], it was reasonable to assume that $\mathbf{9}$ and $\mathbf{1 0}$ may synergize with GSK690693 by acting through same pathway. We confirmed this synergism in DLD1 and DLD1-TxR cells (Supporting Information). Compound 10 significantly improved GSK690693 efficacy with a decrease in its $\mathrm{IC}_{50}$ value (Figure $6 \mathrm{E}, \mathrm{F}$ ). In addition, $\mathbf{1 0}$ more efficiently induced apoptosis in DLD1 (Figure $6 \mathrm{G}$ ) and DLD1-TxR cells (Figure $6 \mathrm{H}$ ).

\section{Conclusions}

Nowadays, the development of MDR to frontline anticancer therapies represents a real issue that requires several multidisciplinary efforts. Identifying and targeting alternative pathways significant for the onset and progression of cancer, as well as for the insurgence of drug resistance to therapeutic agents, is a current challenge. In this respect, the 14-3-3 protein family captured the attention of the scientific community because of its high level of involvement in PPIs. Modulators of 14-3-3 PPIs are in high demand, both as tool to increase our understanding of 14-3-3 biological and pathological functions, and as leads of pharmacological relevance [3a]. By using a well-established computational protocol, we screened a custom virtual library of small molecules against the crystallographic structure of

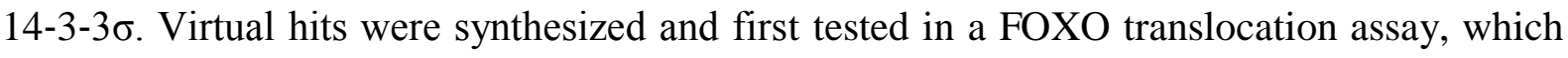
is a powerful tool to rapidly screen for 14-3-3 PPI inhibitors. The most active compounds, 9 and 10, were also found to promote translocation of c-Abl into the nucleus, suggesting that

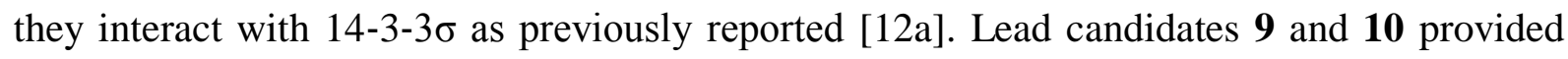
anticancer effects in cells. Particularly, they significantly enhanced the activity of the chemotherapeutic agent doxorubicin and the pan-Akt inhibitor GSK690693 in MDR cancer cells by decreasing P-glycoprotein expression and inducing apoptosis, thus highlighting the potential for using 14-3-3 PPI inhibitors in anticancer combination therapies.

In summary, this multidisciplinary approach provided the small molecules $\mathbf{9}$ and $\mathbf{1 0}$ as tools to deepen the functionality of 14-3-3, particularly in MDR cancer cells, and as lead candidates for further optimization to medicinally active agents. Notably, 9 and $\mathbf{1 0}$ were improved relative to precursor 14-3-3 PPI inhibitors BV01 and BV02.

\section{Experimental Section}

\section{Virtual library design and screening}

400 polar heads and eight lipophilic tails were downloaded from the Sigma-Aldrich and Alfa Aesar online catalogues and reacted in silico to generate the focused virtual library. In silico reactions were performed using a custom script in Python language based on the OpenEye OEChem Toolkit libraries [20]. The closed form of BV02 was also included in the library. The virtual library was then prepared for docking by means of the LigPrep application of the 
Schrödinger's Maestro Suite for molecular modeling, maintaining all parameters at their default value [28].

Molecules were then processed using the docking protocol developed and refined in our previous studies [12a, 16, 17], which led to the identification of the two effective 14-3-3 PPI inhibitors BV01 and BV02. After docking and rescoring, the ten most promising molecules were selected for synthesis, based on a combination of chemical redundancy, visual inspection, and docking score.

\section{Biology}

U2foxRELOC translocation assay: The U2foxRELOC assay has been described previously [18b, 22]. Briefly, cells were seeded at a density of $1.0 \times 10^{5}$ cells $\mathrm{mL}^{-1}$ into black-wall clearbottom 96-well microplates (BD Biosciences). After $12 \mathrm{~h}$ of incubation at $37^{\circ} \mathrm{C}$ with $5 \%$ $\mathrm{CO}_{2}, 2 \mu \mathrm{L}$ of each sample were transferred from the mother plates to the assay plates. Cells were incubated in the presence of the compounds for $1 \mathrm{~h}$. The cells were then fixed, and the nuclei were stained with DAPI (Invitrogen). Finally the plates were washed twice with $1 \times$ phosphate-buffered saline (PBS) and stored at $4{ }^{\circ} \mathrm{C}$ before analysis.

Image acquisition and processing: The $\mathrm{BD}$ Pathway 855 High Content Bioimager (BD Biosciences, San Jose, CA) was used for automated image acquisition. Acquired images were processed using AttoVision software (BD Biosciences). The Bioimager was equipped with a 488/10 nm enhanced GFP (EGFP) excitation filter, a 380/10 nm DAPI excitation filter, a 515 $\mathrm{nm}$ long-pass (LP) EGFP emission filter, and a $435 \mathrm{~nm}$ LP DAPI emission filter. Images were acquired in the DAPI and GFP channels of each well using a $10 \times$ dry objective. The plates were exposed for $0.066 \mathrm{~ms}$ (gain 0) to acquire DAPI images and $0.85 \mathrm{~ms}$ (gain 30) for GFP images. Cells were stained with DAPI to facilitate autofocusing of the microscope and to aid in image segmentation. An image algorithm was applied to allow cell nucleus segmentation based on a local threshold. Our segmentation strategy assumes that the cell cytoplasm surrounds the nucleus. Consequently, cytoplasmic fluorescence intensity was calculated from all the pixels within a circumferential ring surrounding the nuclear ring mask. The width of the ring was defined to be small enough to avoid ambiguities due to irregular cell shape. Based on the definition of cell compartments, the nuclear and cytoplasmic levels of GFP fluorescence were quantified.

Chemicals and drugs for in vitro assays in MDR cancer cells: RPMI 1640 medium, antibiotic-antimycotic solution, L-glutamine, and trypsin/EDTA were purchased from PAA (Vienna, Austria). Fetal bovine serum (FBS), dimethyl sulfoxide (DMSO), and sulforhodamine B (SRB) were obtained from Sigma-Aldrich Chemie GmbH (Germany). Propidium iodide (PI) and annexin-V-FITC (AV) were purchased from Abcam (Cambridge, UK). Doxorubicin (DOX) solution was obtained from EBEWE Arzneimittel GmbH (Vienna, Austria), diluted in sterile water, and $1 \mathrm{mM}$ aliquots were thawed from $-20^{\circ} \mathrm{C}$ before use. GSK690693 was kindly provided by SelleckChem (Houston, TX, USA). GSK690693, as well as 9 and 10, were diluted in DMSO, and $10 \mathrm{mM}$ aliquots were stored at $-20^{\circ} \mathrm{C}$. 
Cells, cell culture, and transfections: NCI-H460, DLD1, and HeLa cell lines were purchased from the American Type Culture Collection (Rockville, MD). NCI-H460/R cells were selected originally from NCI-H460 cells and cultured in a medium containing DOX [29]. DLD1-TxR cells were selected by continuous exposure to stepwise increasing concentrations of paclitaxel from DLD1 cells [30]. HeLa cells stably expressing EGFP-Abl (HeLa EGFPAbl) were obtained by transfection of HeLa cells with the pCEFL EGFP ABL wild-type expression vector [31] using lipofectamine LTX (Life Technologies, Carlsbad, CA), according to the manufacturer's instructions, followed by selection with $2 \mathrm{mg} \mathrm{mL}^{-1} \mathrm{G} 418$ (Sigma-Aldrich) for 3 weeks. MDR cancer cell lines (NCI-H460/R and DLD1-TxR) and their sensitive counterparts were maintained in RPMI 1640 medium supplemented with $10 \%$ FBS, $2 \mathrm{~mm}$ l-glutamine, and $10000 \mathrm{U} \mathrm{mL}^{-1}$ penicillin, $10 \mathrm{mg} \mathrm{mL}^{-1}$ streptomycin, $25 \mu \mathrm{g} \mathrm{mL}^{-1}$ amphotericin B solution. HeLa EGFP-Abl were maintained in DMEM supplemented with $10 \%$ FBS, $2 \mathrm{~mm}$ l-glutamine, $10000 \mathrm{U} \mathrm{mL}^{-1}$ penicillin, and $10 \mathrm{mg} \mathrm{mL}^{-1}$ streptomycin and were constantly kept under selective pressure with $2 \mathrm{mg} \mathrm{mL}^{-1} \mathrm{G} 418$. Selective medium was replaced with regular growth medium on the day before experiments. All cell lines were subcultured at $72 \mathrm{~h}$ intervals using $0.25 \%$ trypsin/EDTA and seeded into fresh medium at the following densities: 8000 cells cm${ }^{-2}$ for NCI-H460 and DLD1, and 16000 cells cm$^{-2}$ for NCI-H460/R, DLD1-TxR, and HeLa EGFP-Abl cells. The pCEFL EGFP-Abl expression vector was a kind gift from Ricardo Sánchez-Prieto (Universidad de Castilla-La Mancha UCLM).

Immunofluorescence, confocal microscopy, and intensitometric analysis of fluorescence: Cells were washed with PBS, then fixed with $4 \%$ paraformaldehyde in PBS for 20 min and permeabilized with $0.2 \%$ Triton X-100 in PBS for $15 \mathrm{~min}$. Nuclei were stained with a solution of $1.5 \mu \mathrm{M}$ of 4',6-diamidino-2-phenylindole (DAPI; Sigma Aldrich) in PBS for 5 min. Coverslips were mounted in fluorescence mounting medium (Dako). Samples were visualized on a TSC SP5 confocal microscope (Leica, 5100000750), installed on an inverted LEICA DMI 6000CS (10741320) microscope and equipped with an oil immersion PlanApo $40 \times 1.25$ NA objective. Images were acquired using LAS AF acquisition software (Leica). Intensitometric analysis of fluorescence was performed using the Quantitation Module of the Volocity software (PerkinElmer Life Science). Briefly, total nuclear EGFP fluorescence, defined as EGFP signal co-staining with DAPI nuclear dye, was measured in five representative confocal fields for each experimental condition. The resulting mean values \pm SD are expressed as a percentage of nuclear EGFP fluorescence. Five representative fields were acquired and analyzed for each sample. Significance ( $p$ value) was assessed by one-way ANOVA test. Asterisks were attributed for the following significance values: ${ }^{*} p<0.05$, $* * p<0.01$.

$S R B$ assays: Cells grown in $25 \mathrm{~cm}^{2}$ tissue flasks were trypsinized, seeded into flat-bottomed 96-well tissue culture plates (2000 cells per well for NCI-H460 and DLD1 cells, 4000 cells per well for NCI-H460/R and DLD1-TxR cells) and incubated overnight. Treatment with DOX (2.5-50 nM for NCI-H460 and 100-2500 nM for NCI-H460/R), GSK690693 (5-100 $\mu \mathrm{M})$, and $\mathbf{9}$ and $10(5-100 \mu \mathrm{M})$ lasted $72 \mathrm{~h}$. The combined effects of $\mathbf{9}$ and $\mathbf{1 0}(10 \mu \mathrm{M})$ with DOX or GSK690693 were studied in simultaneous treatments. The cell growth inhibitory 
assay was performed after $72 \mathrm{~h}$. The cellular proteins were stained with SRB, following slightly the modified protocol of Skehan et al [32]. Briefly, the cells in 96-well plates were fixed in $50 \%$ trichloroacetic acid $\left(50 \mu \mathrm{L}\right.$ per well) for $1 \mathrm{~h}$ at $4{ }^{\circ} \mathrm{C}$, rinsed in tap water, and stained with $0.4 \%(w / v) \mathrm{SRB}$ in $1 \%$ acetic acid $(50 \mu \mathrm{L}$ per well) for $30 \mathrm{~min}$ at room temperature. The cells were then rinsed three times in $1 \%$ acetic acid to remove the unbound stain. The protein-bound stain was extracted with $200 \mu \mathrm{L} 10 \mathrm{mM}$ Tris base $(\mathrm{pH} 10.5)$ per well. The optical density was read at $540 \mathrm{~nm}$ with correction at $670 \mathrm{~nm}$ in a LKB 5060-006 Microplate Reader (Vienna, Austria). Results were expressed as the percent of growth inhibition (I) determined according to Equation (1):

$$
\mathrm{I}(\%)=\left(1-\left(\mathrm{A}_{\text {treated sample }} / \mathrm{A}_{\text {untreated control }}\right)\right) \times 100
$$

in which $A$ is the absorbance. $\mathrm{IC}_{50}$ values were defined as the concentration of the drug that inhibited cell growth by $50 \%$ and were calculated by linear regression analysis using Excel software. Statistical analysis was performed by Statistica 6.0 software. The differences between groups were examined by Student's $t$-test, and statistical significance is denoted as $* p<0.05$ or $* * p<0.01$.

Combination effect analysis: The nature of the interaction between DOX/GSK690693 and 9 and 10 was analyzed using CalcuSyn software that uses the combination index (CI) method of Chou and Talalay [33], based on the multiple drug effect equation. We used at least three data points for each single drug in each designed experiment. The non-constant ratio combination was chosen to assess the effect of both drugs in combination. We have presented the results as normalized isobolograms. Values of $\mathrm{CI}<1$ point to a pronounced additive effect or synergism, that is, the smaller value, the greater the degree of synergy. A value of $\mathrm{CI}=1$ indicates an additive effect, and values of $\mathrm{CI}>1$ point to an antagonistic effect. Each $\mathrm{CI}$ ratio shown here represents the mean value derived from two separate experiments.

DOX accumulation assays: DOX accumulation was analyzed by flow cytometry using the ability of DOX to emit fluorescence. The intensity of the fluorescence was proportional to DOX accumulation. Studies were carried out after $72 \mathrm{~h}$ treatment. NCI-H460/R cells were cultured in $25 \mathrm{~cm}^{2}$ flasks, trypsinized, and resuspended in $10 \mathrm{~mL}$ centrifuge tubes in a DOXcontaining medium $(20 \mu \mathrm{M})$. The cells were then incubated at $37^{\circ} \mathrm{C}$ in $5 \% \mathrm{CO}_{2}$ for $2 \mathrm{~h}$. At the end of the accumulation period, the cells were pelleted by centrifugation, washed with PBS, and placed in cold PBS. The samples were kept on ice in the dark until analysis using a FACSCalibur flow cytometer (Becton Dickinson, Oxford, UK). The fluorescence of DOX was assessed on fluorescence channel 2 (FL2). A minimum of 10000 events were assayed for each sample.

Flow cytometric analysis of P-glycoprotein expression: Flow cytometry was used to measure P-glycoprotein expression levels in MDR cancer cells. Cells were collected by trypsinization, washed in ice-cold PBS, and then directly immunostained by FITC-conjugated anti-Pglycoprotein antibody according to the manufacturers' protocol (BD Biosciences, UK). An isotype control, IgG2bк (Abcam, Cambridge, UK), was evaluated for each experimental sample to discriminate the level of background fluorescence of negative cells. The samples 
were kept on ice in the dark until analysis using a FACSCalibur flow cytometer. The fluorescence of FITC-conjugated anti-P-glycoprotein was assessed on fluorescence channel 1 (FL1). A minimum of 10000 events were assayed for each sample (the gate excluded cell debris and death cells), and the obtained results were analyzed using Cell Quest Pro Software (Becton Dickinson). The differences in curve shapes were quantified using a KomogorovSmirnov nonparametric statistic. P values were calculated (available upon request) using CellQuest Pro.

Cell death detection: The percentages of apoptotic, necrotic, and viable cells were determined by AV and PI labeling. DLD1 and DLD1-TxR cells were plated and incubated overnight in six-well plates at a density of 50000 cells per well. Cells were subjected to single treatments with $10 \mu \mathrm{M}$ of 9 and 10, as well as GSK690693 $(20 \mu \mathrm{M}$ for DLD1 and $50 \mu \mathrm{M}$ for DLD1TxR). After $72 \mathrm{~h}$, the attached and floating cells were collected by centrifugation. The cell pellet was re-suspended in $100 \mu \mathrm{L}$ of binding buffer, supplemented with $5 \mu \mathrm{L}$ AV and $5 \mu \mathrm{L}$ PI, according to manufacturer's instructions. After the incubation period ( $5 \mathrm{~min}$ at room temperature), an additional $400 \mu \mathrm{L}$ of binding buffer was added, and AV/PI staining was analyzed within $1 \mathrm{~h}$ by flow cytometry. The fluorescence intensity (green FL1-H and red FL2H) was measured on a FACSCalibur flow cytometer. In each sample, 10000 cells were recorded (gated to exclude cell debris), and the percentages of viable (AV-/PI-), early apoptotic $(\mathrm{AV}+/ \mathrm{PI}-)$, apoptotic and necrotic $(\mathrm{AV}+/ \mathrm{PI}+)$, and already dead (AV-/PI+) cells were analyzed by CellQuest Pro data analysis software.

\section{Chemistry}

All commercially available chemicals were used as purchased. $\mathrm{CH}_{2} \mathrm{Cl}_{2}$ was dried over calcium hydride, whereas THF was dried over Na/benzophenone prior to use. DMF was purchased in an anhydrous form from Sigma-Aldrich. Anhydrous reactions were run under a positive pressure of dry $\mathrm{N}_{2}$ or argon. TLC was carried out using Merck TLC plates (silica gel $60 \mathrm{~F}_{254}$ ). Chromatographic purifications were performed on columns packed with Merck 60 silica gel, 23-400 mesh, using the flash technique. ${ }^{1} \mathrm{H} N M R$ and ${ }^{13} \mathrm{C}$ NMR spectra were recorded at $400 \mathrm{MHz}$ on a Bruker Avance DPX400. Chemical shifts are reported relative to tetramethylsilane at $\delta=0.00 \mathrm{ppm}$. Melting points were taken using a Gallenkamp melting point apparatus and are uncorrected. Mass spectra (MS) data were obtained using an Agilent 1100 LC/MSD VL system (G1946C) with a $0.4 \mathrm{~mL} \mathrm{~min}^{-1}$ flow rate using a binary solvent system of $\mathrm{MeOH} / \mathrm{H}_{2} \mathrm{O}$ (95:5). UV detection was monitored at $254 \mathrm{~nm}$. MS were acquired in positive and negative mode scanning over a mass range of $m / z, 100-1500$. The following ion source parameters were used: drying gas flow $9 \mathrm{~mL} \mathrm{~min}^{-1}$; nebulizer pressure $40 \mathrm{psig}$; drying gas temperature $350{ }^{\circ} \mathrm{C}$.

HPLC analysis was performed with an Agilent 1100 LC/MSD VL system constituted by a vacuum solvent degassing unit, a binary high-pressure gradient pump, an 1100 series UV detector, and a 1100 MSD model VL bench-top mass spectrometer. The Agilent 1100 series mass spectra detection (MSD) single quadrupole instrument was equipped with an orthogonal spray API-ES (Agilent Technologies). The following ion source parameters were used: drying gas flow $9 \mathrm{~mL} \mathrm{~min}^{-1}$; nebulizer pressure $40 \mathrm{psig}$; drying gas temperature $350^{\circ} \mathrm{C}$. UV 
detection was monitored at $254 \mathrm{~nm}$. LC-ESIMS determination was performed by operating the MSD in the negative ion mode. Spectra were acquired over a scan range of $\mathrm{m} / \mathrm{z}, 100-1500$ using a step size of $0.1 \mu \mathrm{s}$.

LC analyses were conducted via HPLC using a Polaris $\mathrm{C}_{18}$ column $(150 \times 4.6 \mathrm{~mm}, 5 \mu \mathrm{m}$ particle size) at a flow rate of $0.4 \mathrm{~mL} \mathrm{~min}^{-1}$ with a gradient mobile phase composed of $\mathrm{MeOH}$ and $1 \% \mathrm{HCOOH}-\mathrm{H}_{2} \mathrm{O}[t=0: 0 \% \mathrm{MeOH}, t=20 \mathrm{~min}: 98 \% \mathrm{MeOH}, t=25 \mathrm{~min}: 0 \% \mathrm{MeOH}]$ with an injection volume of $20 \mu \mathrm{L}$.

2-(1,5-Dimethyl-3-oxo-2-phenyl-2,3-dihydro-1 $H$-pyrazol-4-yl)-1,3-dioxo-2,3-dihydro-1Hisoindole-5-carboxylic acid (9): 4-Aminoantipyrine (12; $0.78 \mathrm{mmol}, 3.00$ equiv) was dissolved in $1 \mathrm{~mL}$ anhydrous DMF, then trimellitic anhydride (11; $0.26 \mathrm{mmol}, 1.00$ equiv) and DMAP (10.0 mg) were added, and the mixture was stirred at $110^{\circ} \mathrm{C}$ for $12 \mathrm{~h}$. The suspension was allowed to cool to room temperature and was then diluted with $\mathrm{H}_{2} \mathrm{O}(5 \mathrm{~mL})$. The resulting white precipitate was filtered under reduced pressure, thoroughly washed with $\mathrm{H}_{2} \mathrm{O}$ and hexane, and then dried over $\mathrm{P}_{2} \mathrm{O}_{5}$ to give 9 as a white solid (yield: $45 \mathrm{mg}, 46 \%$ ): ${ }^{1} \mathrm{H}$ NMR (400 MHz, [D $\mathrm{D}_{6}$ DMSO): $\delta=13.72(\mathrm{~s}, 1 \mathrm{H}), 8.40(\mathrm{~d}, J=8 \mathrm{~Hz}, 1 \mathrm{H}), 8.29$ (s, $\left.1 \mathrm{H}\right), 8.07$ (d, $J=8 \mathrm{~Hz}, 1 \mathrm{H}), 7.53(\mathrm{~m}, 2 \mathrm{H}), 7.38(\mathrm{~m}, 3 \mathrm{H}), 3.27(\mathrm{~s}, 3 \mathrm{H}), 2.24 \mathrm{ppm}(\mathrm{s}, 3 \mathrm{H}) ;{ }^{13} \mathrm{C} \mathrm{NMR}(100$ MHz, [D $\mathrm{D}_{6}$ DMSO): $\delta=166.5,166.2,161.0,154.4,137.1,136.1,135.2,134.9,132.4,129.7$, 127.6, 125.1, 124.5, 124.0, 100.0, 35.7, 10.9 ppm; MS (ESI) $m / z: 376[M-\mathrm{H}]^{-}$; purity: $98.8 \%$; room temperature: $11.7 \mathrm{~min}$.

\section{Dimethyl}

5-(3-(1,5-dimethyl-3-oxo-2-phenyl-2,3-dihydro-1H-pyrazol-4yl)ureido)isophthalate (10): 4-Aminoantipyrine (12; $0.23 \mathrm{mmol}, 1.00$ equiv) was added to a solution of dimethyl 5 -isocyanatoisophthalate $(\mathbf{1 3} ; 0.23 \mathrm{mmol}, 1.00$ equiv) in anhydrous $\mathrm{CH}_{2} \mathrm{Cl}_{2}(15 \mathrm{~mL})$. The reaction mixture was stirred at room temperature under $\mathrm{N}_{2}$ atmosphere until TLC showed the disappearance of the starting materials. The resulting precipitate was filtered under reduced pressure and washed with hexane to give $\mathbf{1 0}$ as a white solid (yield: 69 mg, $69 \%$ ): ${ }^{1} \mathrm{H}$ NMR (400 MHz, $\mathrm{CDCl}_{3}$ ): $\delta=8.90$ (s, $\left.1 \mathrm{H}\right) ; 8.20(\mathrm{~s}, 1 \mathrm{H}) ; 8.16(\mathrm{~s}, 1 \mathrm{H}) ; 8.04$ (s, $2 \mathrm{H}) ; 7.50$ (m, $2 \mathrm{H}) ; 7.39$ (d, J=8 Hz, $2 \mathrm{H}) ; 7.35$ (t, $J=7.2 \mathrm{~Hz}, 1 \mathrm{H}) ; 3.81$ (s, $6 \mathrm{H}) ; 3.11$ (s, $3 \mathrm{H})$; $2.22 \mathrm{ppm}(\mathrm{s}, 3 \mathrm{H}) ;{ }^{13} \mathrm{C}$ NMR $\left(100 \mathrm{MHz}, \mathrm{CDCl}_{3}\right): \delta=166.5,163.3,155.0,151.1,140.4,134.1$, $131.1,130.0,128.6,126.0,124.5,124.1,108.1,52.4,35.6,11.7$ ppm; MS (ESI) m/z: 439 $[M+\mathrm{H}]^{+}, 461[M+\mathrm{Na}]^{+}$; purity: $98.2 \%$; room temperature: $12.2 \mathrm{~min}$.

\section{Acknowledgements}

The authors acknowledge networking support by the COST Action CM1106 StemChem"Chemical Approaches to Targeting Drug Resistance in Cancer Stem Cells". Partial financial support was provided by Lead Discovery Siena, Srl and the Ministry of Education, Science, and Technological Development of Serbia (grant no. III 41031). R.H. is the recipient of a Fundação para a Ciência e a Tecnologia (FCT) 2012 research grant (no. SFRH/BPD/84634/2012). The authors thank Dr. Federico Falchi for his contribution to the initial stage of this project. 


\section{References}

[1] D. K. Morrison, Trends Cell Biol. 2009, 19, 16- 23.

[2] a) A. K. Gardino, S. J. Smerdon, M. B. Yaffe, Semin. Cancer Biol. 2006, 16, 173- 182; b)

E. Kjarland, T. J. Keen, R. Kleppe, Curr. Pharm. Biotechnol. 2006, 7, 217- 223.

[3] a) M. Mori, G. Vignaroli, M. Botta, Drug Discovery Today Technol. 2013, 10, e 541-e 547; b) T. Obsil, V. Obsilova, Semin. Cell Dev. Biol. 2011, 22, 663- 672.

[4] a) P. M. Chan, Y.-W. Ng, E. Manser, Mol. Cell. Proteomics 2011, 10, M 110.005157; b) C. Johnson, M. Tinti, N. T. Wood, D. G. Campbell, R. Toth, F. Dubois, K. M. Geraghty, B. H. Wong, L. J. Brown, J. Tyler, A. Gernez, S. Chen, S. Synowsky, C. MacKintosh, Mol. Cell. Proteomics 2011, 10, M 110.005751; c) B. A. Joughin, B. Tidor, M. B. Yaffe, Protein Sci. 2005, 14, 131- 139.

[5] a) L. G. Milroy, L. Brunsveld, C. Ottmann, ACS Chem. Biol. 2013, 8, 27- 35; b) C. Ottmann, Bioorg. Med. Chem. 2013, 21, 4058- 4062.

[6] a) M. Foote, Y. Zhou, Int. J. Biochem. Mol. Biol. 2012, 3, 152- 164; b) E. Wilker, M. B. Yaffe, J. Mol. Cell. Cardiol. 2004, 37, 633-642.

[7] a) D. Berg, C. Holzmann, O. Riess, Nat. Rev. Neurosci. 2003, 4, 752- 762; b) M. K. Dougherty, D. K. Morrison, J. Cell Sci. 2004, 117, 1875- 1884.

[8] a) H. Fu, J. Coburn, R. J. Collier, Proc. Natl. Acad. Sci. USA 1993, 90, 2320- 2324; b) C. Ottmann, L. Yasmin, M. Weyand, J. L. Veesenmeyer, M. H. Diaz, R. H. Palmer, M. S. Francis, A. R. Hauser, A. Wittinghofer, B. Hallberg, EMBO J. 2007, 26, 902-913.

[9] R. Kleppe, A. Martinez, S. O. Doskeland, J. Haavik, Semin. Cell Dev. Biol. 2011, 22, $713-$ 719.

[10] a) M. F. Leal, D. Q. Calcagno, S. Demachki, P. P. Assumpcao, R. Chammas, R. R. Burbano, M. D. C. Smith, World J. Gastroenterol. 2012, 18, 1531- 1537; b) Y. Liu, R. F. Tian, Y. M. Li, W. P. Liu, L. Cao, X. L. Yang, W. D. Cao, X. Zhang, Brain Res. 2010, 1336, 98- 102; c) C. L. Neal, D. Yu, Expert Opin. Ther. Targets 2010, 14, 1343-1354; d) DD. Zang, X. Li, L. Zhang, Clin. Exp. Med. 2010, 10, 221- 228.

[11] W. H. Zhou, F. Tang, J. Xu, X. Wu, Z. Y. Feng, H. G. Li, D. J. Lin, C. K. Shao, Q. Liu, BMC Cancer 2011, 11, 397.

[12] a) M. Mancini, V. Corradi, S. Petta, E. Barbieri, F. Manetti, M. Botta, M. A. Santucci, J. Pharmacol. Exp. Ther. 2011, 336, 596-604; b) K. Yoshida, T. Yamaguchi, T. Natsume, D. Kufe, Y. Miki, Nat. Cell Biol. 2005, 7, 278- 285.

[13] a) B. Han, H. Xie, Q. Chen, J. T. Zhang, Mol. Cancer Ther. 2006, 5, 903- 912; b) Y. Liu, H. Liu, B. Han, J. T. Zhang, Cancer Res. 2006, 66, 3248- 3255. 
[14] a) C. Anders, Y. Higuchi, K. Koschinsky, M. Bartel, B. Schumacher, P. Thiel, H. Nitta, R. Preisig-Muller, G. Schlichthorl, V. Renigunta, J. Ohkanda, J. Daut, N. Kato, C. Ottmann, Chem. Biol. 2013, 20, 583- 593; b) AA. Richter, R. Rose, C. Hedberg, H. Waldmann, C. Ottmann, Chemistry 2012, 18, 6520-6527; c) R. Rose, S. Erdmann, S. Bovens, A. Wolf, M. Rose, S. Hennig, H. Waldmann, C. Ottmann, Angew. Chem. Int. Ed. 2010, 49, 4129- 4132; Angew. Chem. 2010, 122, 4223- 4226.

[15] H. Wu, J. Ge, S. Q. Yao, Angew. Chem. Int. Ed. 2010, 49, 6528- 6532; Angew. Chem. $2010,122,6678-6682$.

[16] V. Corradi, M. Mancini, F. Manetti, S. Petta, M. A. Santucci, M. Botta, Bioorg. Med. Chem. Lett. 2010, 20, 6133-6137.

[17] V. Corradi, M. Mancini, M. A. Santucci, T. Carlomagno, D. Sanfelice, M. Mori, G. Vignaroli, F. Falchi, F. Manetti, M. Radi, M. Botta, Bioorg. Med. Chem. Lett. 2011, 21, 6867-6871.

[18] a) Y. W. Su, Z. Hao, A. Hirao, K. Yamamoto, W. J. Lin, A. Young, G. S. Duncan, H. Yoshida, A. Wakeham, P. A. Lang, K. Murakami, H. Hermeking, B. Vogelstein, P. Ohashi, T. W. Mak, Proc. Natl. Acad. Sci. USA 2011, 108, 1555- 1560; b) F. Zanella, A. Rosado, B. Garcia, A. Carnero, W. Link, ChemBioChem 2008, 9, 2229- 2237; c) F. Zanella, A. Rosado, B. Garcia, A. Carnero, W. Link, BMC Cell Biol. 2009, 10, 14.

[19] E. W. Wilker, R. A. Grant, S. C. Artim, M. B. Yaffe, J. Biol. Chem. 2005, 280, 1889118898.

[20] OpenEye Toolkits 2013, OpenEye Scientific Software, Santa Fe, NM (USA), http://www.eyesopen.com.

[21] M. C. Hung, W. Link, J. Cell Sci. 2011, 124, 3381- 3392.

[22] W. Link, J. Oyarzabal, B. G. Serelde, M. I. Albarran, O. Rabal, A. Cebria, P. Alfonso, J. Fominaya, O. Renner, S. Peregrina, D. Soilan, P. A. Ceballos, A. I. Hernandez, M. Lorenzo, P. Pevarello, T. G. Granda, G. Kurz, A. Carnero, J. R. Bischoff, J. Biol. Chem. 2009, 284, 28392-28400.

[23] a) F. Zanella, N. R. dos Santos, W. Link, Traffic 2013, 14, 247- 258; b) F. Zanella, J. B. Lorens, W. Link, Trends Biotechnol. 2010, 28, 237- 245.

[24] F. Zanella, A. Rosado, F. Blanco, B. R. Henderson, A. Carnero, W. Link, Assay Drug Dev. Technol. 2007, 5, 333-341.

[25] J. Bauer, J. Rademann, Tetrahedron Lett. 2003, 44, 5019- 5023.

[26] J. Clayden, H. Turner, M. Pickworth, T. Adler, Org. Lett. 2005, 7, 3147- 3150.

[27] R. Kumar, S. J. Blakemore, C. E. Ellis, E. F. Petricoin III, D. Pratt, M. Macoritto, A. L. Matthews, J. J. Loureiro, K. Elliston, BMC Genomics 2010, 11, 419. 
[28] a) LigPrep ver. 2.5, Schrödinger LLC, New York, NY (USA), 2011; b) Maestro ver. 9.2, Schrödinger LLC, New York, NY (USA), 2011.

[29] M. Pesic, J. Z. Markovic, D. Jankovic, S. Kanazir, I. D. Markovic, L. Rakic, S. Ruzdijic, J. Chemother. 2006, 18, 66-73.

[30] A. Podolski-Renić, T. Andelković, J. Banković, N. Tanić, S. Ruzdijić, M. Pesić, Biomed. Pharmacother. 2011, 65, 345-353.

[31] E. M. Galan-Moya, J. Hernandez-Losa, C. I. A. Luquero, M. A. de La Cruz-Morcillo, C. Ramirez-Castillejo, J. L. Callejas-Valera, A. Arriaga, A. F. Aranburo, S. R. y Cajal, J. S. Gutkind, R. Sanchez-Prieto, Int. J. Cancer 2008, 122, 289- 297.

[32] P. Skehan, R. Storeng, D. Scudiero, A. Monks, J. McMahon, D. Vistica, J. T. Warren, H. Bokesch, S. Kenney, M. R. Boyd, J. Natl. Cancer Inst. 1990, 82, 1107- 1112.

[33] T. C. Chou, P. Talalay, Adv. Enzyme Regul. 1984, 22, 27- 55. 

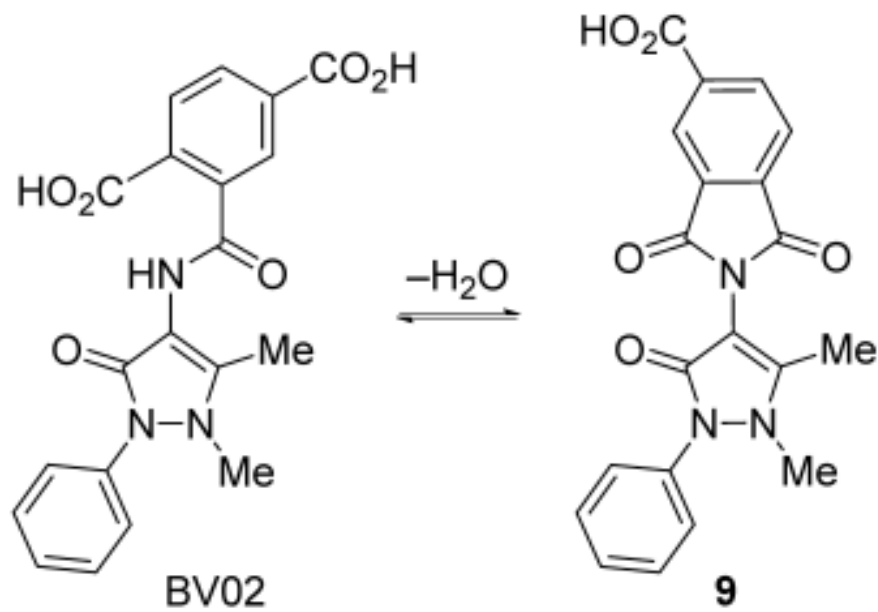

Scheme 1

Dehydration process of BV02 (open dicarboxylic form) to give $\mathbf{9}$ (closed phthalimide form). 


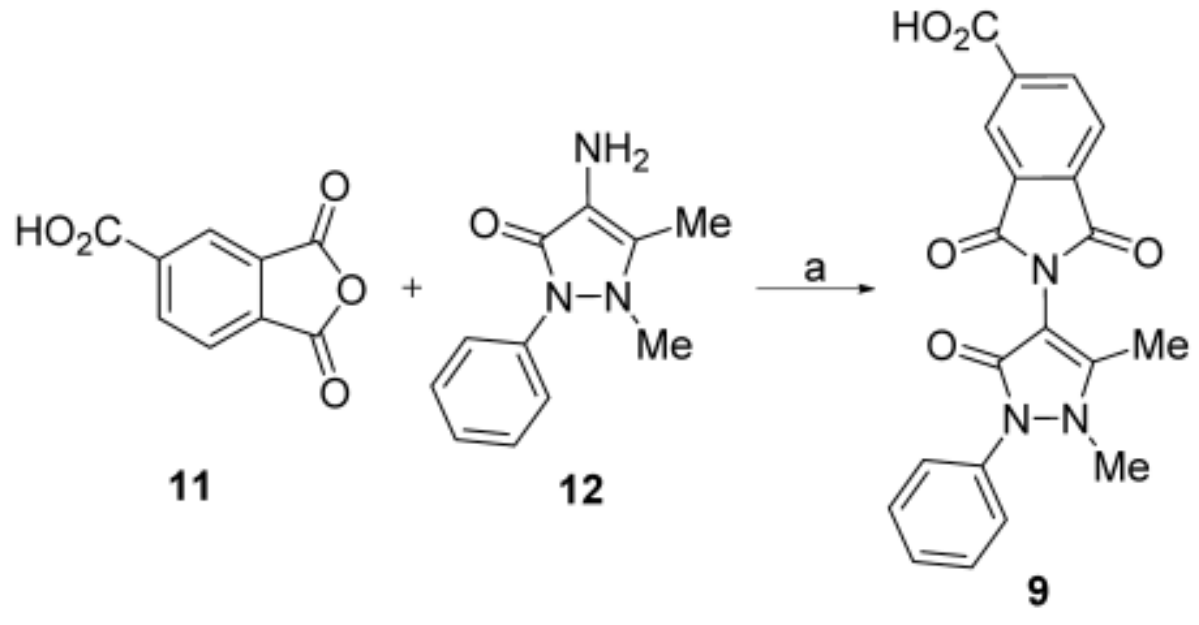

Scheme 2

Synthesis of potential 14-3-3 protein-protein interaction inhibitor 9. Reagents and conditions:

a) DMAP, anhydrous DMF, $110^{\circ} \mathrm{C}, 12 \mathrm{~h}$. 


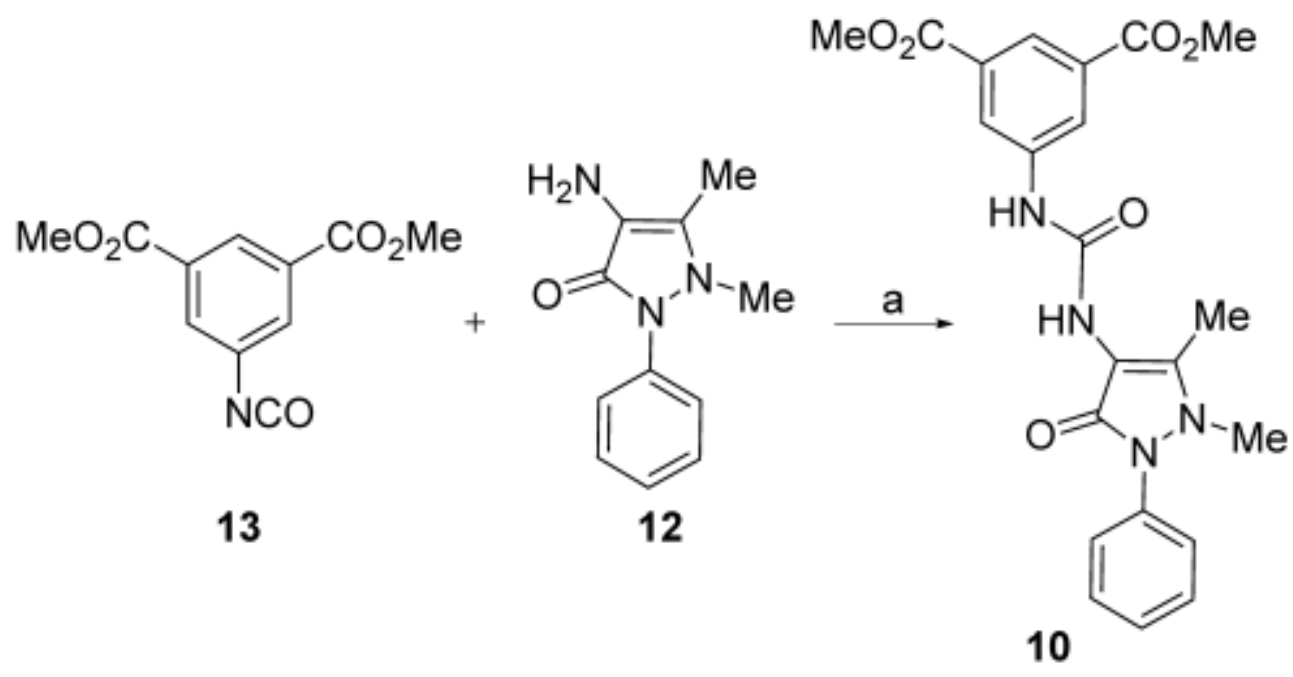

Scheme 3

Synthesis of potential 14-3-3 protein-protein interaction inhibitor 10. Reagents and conditions: a) $\mathrm{CH}_{2} \mathrm{Cl}_{2}$, RT, $24 \mathrm{~h}$. 


\section{Figure legends}

Figure 1. Structures of BV01, BV02, and the ten small molecules selected by virtual screening.

Figure 2. Identification of active compounds using the U2foxRELOC assay. U2foxRELOC cells were seeded in 96-well plates and exposed for $1 \mathrm{~h}$ to the putative 14-3-3 PPI inhibitors. Each assay plate contained eight wells of cell samples treated with $20 \mu \mathrm{M}$ LY294002 (LY) and eight wells treated with $1 \%$ DMSO (negative control). Cytoplasmic ratios of fluorescence intensity were determined by dividing the fluorescence intensity of the nucleus by the cytoplasmic fluorescence intensity. A threshold ratio greater than 1.8 was employed to define nuclear accumulation of the fluorescent signal for each cell. On the basis of this procedure, we calculated the percentage of cells per well displaying nuclear translocation. Compounds that induced a nuclear accumulation of the fluorescent signal greater than $60 \%$ of that obtained from wells treated with $20 \mu \mathrm{M}$ LY294002 were considered hits. The mean of duplicates \pm SD is shown for each compound.

Figure 3. Predicted binding mode of the most active 14-3-3 PPI inhibitors. The dockingbased binding modes of A) $\mathbf{8}$, B) $\mathbf{9}$, and C) $\mathbf{1 0}$ are reported. Small molecules are shown as cyan sticks with the crystallographic structure of 14-3-3 $\sigma$ (PDB ID: 1YWT) shown as a grey ribbon structure. 14-3-3 $\sigma$ residues involved in binding to small molecules are shown as green sticks and are labeled. Hydrogen bonds are highlighted as magenta dashed lines.

Figure 4. 14-3-3 PPI inhibitors promote nuclear translocation of c-Abl. Confocal microscopy images showing subcellular localization of c-Abl in HeLa EGFP-Abl cells A) untreated or treated with either B) 9 or C) $\mathbf{1 0}$ at $25 \mu \mathrm{M}$ for $24 \mathrm{~h}$. D) Intensitometric analysis of nuclear EGFP fluorescence on HeLa EGFP-Abl cells treated with increasing concentrations of either $\mathbf{9}$ or $\mathbf{1 0}$ for $24 \mathrm{~h}$; bars represent the mean \pm SD of the nuclear EGFP fluorescence intensity of five representative fields; ${ }^{*} p<0.05, * * p<0.01$.

Figure 5. 14-3-3 PPI inhibitors increase doxorubicin (DOX) efficacy in non-small-cell lung carcinoma cell lines: Cell growth inhibition assessed by a sulforhodamine B (SRB) assay after $72 \mathrm{~h}$ treatment in A) NCI-H460 and B) NCI-H460/R cells. Cell growth inhibition by DOX alone and in combination with either $\mathbf{9}$ or $\mathbf{1 0}$ (at $10 \mu \mathrm{M}$ ) in C) NCI-H460 and E) NCI-H460/R cells. $\mathrm{IC}_{50}$ values for DOX calculated by Forecast linear regression in Excel when DOX was applied alone and in combination with either $\mathbf{9}$ or $\mathbf{1 0}$ (at $10 \mu \mathrm{M}$ ) in D) NCI-H460 and F) NCIH460/R cells. G) Flow-cytometric profiles of $20 \mu \mathrm{M}$ DOX accumulation after $2 \mathrm{~h}$ in NCIH460/R cells; a minimum of 10000 events were collected for each experiment; $* * p<0.01$.

Figure 6. 14-3-3 PPI inhibitors modulate P-glycoprotein (P-gp) expression and synergize with pan-Akt inhibitor in colon carcinoma cells. Flow-cytometric profiles of P-gp expression in DLD1-TxR cells, assessed after $72 \mathrm{~h}$ treatment with A) $9(10 \mu \mathrm{M}), \mathrm{B}) \mathbf{1 0}(10 \mu \mathrm{M})$, and C) pan-Akt inhibitor GSK690693 $(20 \mu \mathrm{M})$. D) Mean P-gp fluorescence intensity assessed by 
FITC-anti-P-gp monoclonal antibody in DLD1-TxR cells; a minimum of 10000 events were collected for each experiment. IC 50 values for pan-Akt inhibitor GSK690693 calculated by Forecast linear regression in Excel when GSK690693 was applied alone and in combination with either 9 or $\mathbf{1 0}$ (at $10 \mu \mathrm{M}$ ) in E) DLD1 and F) DLD1-TxR cells. G) Cell death analysis of DLD1 cells treated with 9 or $\mathbf{1 0}$ (at $100 \mu \mathrm{M})$, as well as with GSK690693 (20 $\mu \mathrm{M})$ for $72 \mathrm{~h}$. H) Cell death analysis of DLD1-TxR cells treated with $\mathbf{9}$ or $\mathbf{1 0}$ (at $100 \mu \mathrm{M}$ ), as well as with GSK690693 $(50 \mu \mathrm{M})$ for $72 \mathrm{~h}$. Samples were analyzed for green fluorescence (annexin-VFITC, FL1-H) and red fluorescence (propidium iodide, FL2-H) by flow cytometry. The assay distinguishes viable cells (AV-/PI-), apoptotic cells (AV+/PI-), late apoptotic and necrotic cells $(\mathrm{AV}+\mathrm{PI}+)$ and secondary necrotic or dead cells $(\mathrm{AV}-/ \mathrm{PI}+) ;{ }^{*} p<0.05,{ }^{*} p<0.01$. 
Figure 1

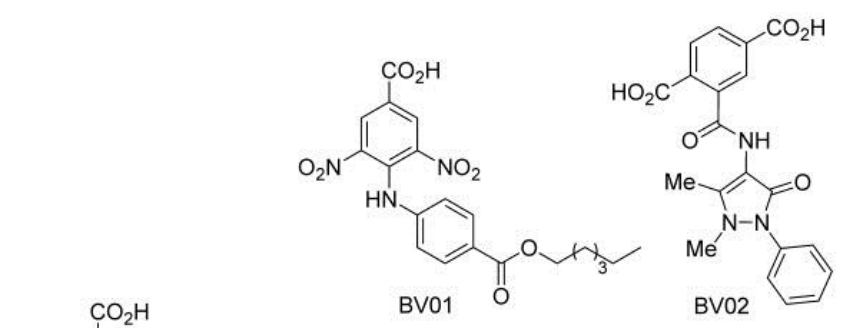

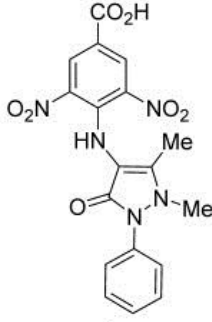<smiles>O=C(O)c1cc([N+](=O)[O-])c(NC(CCc2ccccc2)c2ccccc2)c([N+](=O)[O-])c1</smiles><smiles>COc1cccc(N=O)c1</smiles>

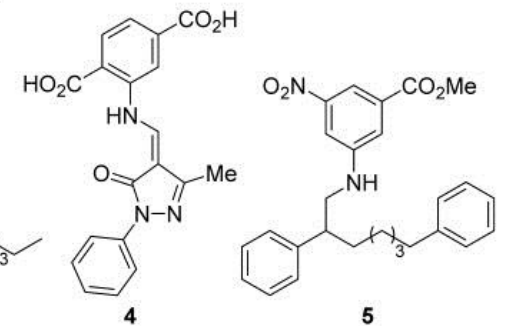<smiles>Cc1nn(-c2ccccc2)c(O)c1C(=O)Nc1cccc([N+](=O)[O-])c1</smiles><smiles></smiles><smiles>C[N+](=O)C1=C(NC(=O)Nc2cc(C(=O)O)cc(C(=O)O)c2)C(=O)N(c2ccccc2)C1=O</smiles><smiles>CN(C)c1c(C(=O)N2C(=O)c3ccc(C(=O)O)cc3C2=O)n(-c2ccccc2)c(=O)n1C</smiles><smiles>COCc1cc(NC(=O)Nc2c(C)n(C)n(-c3ccccc3)c2=O)cc(C(=O)OC)c1</smiles>

10 
Figure 2

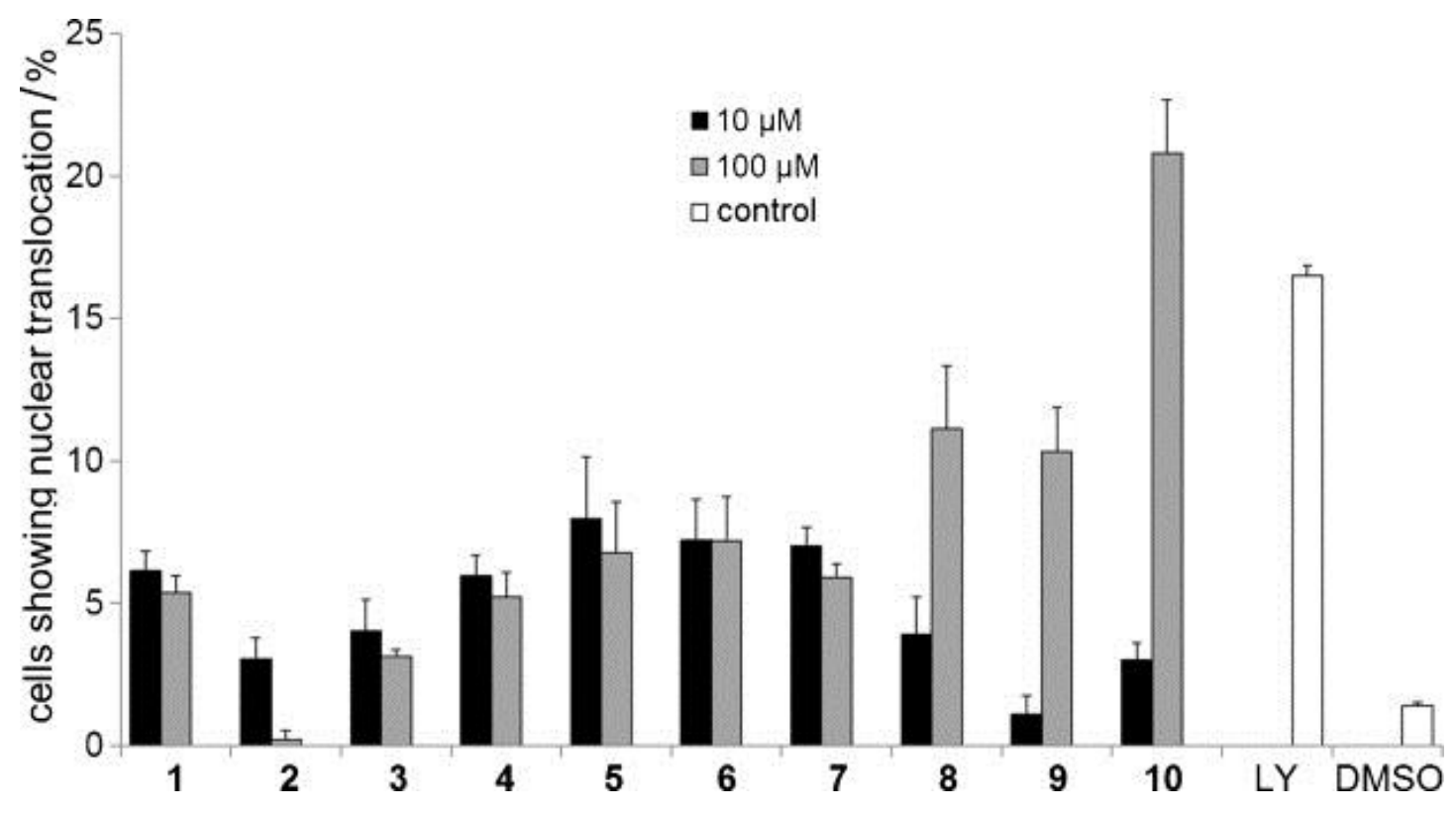


Figure 3

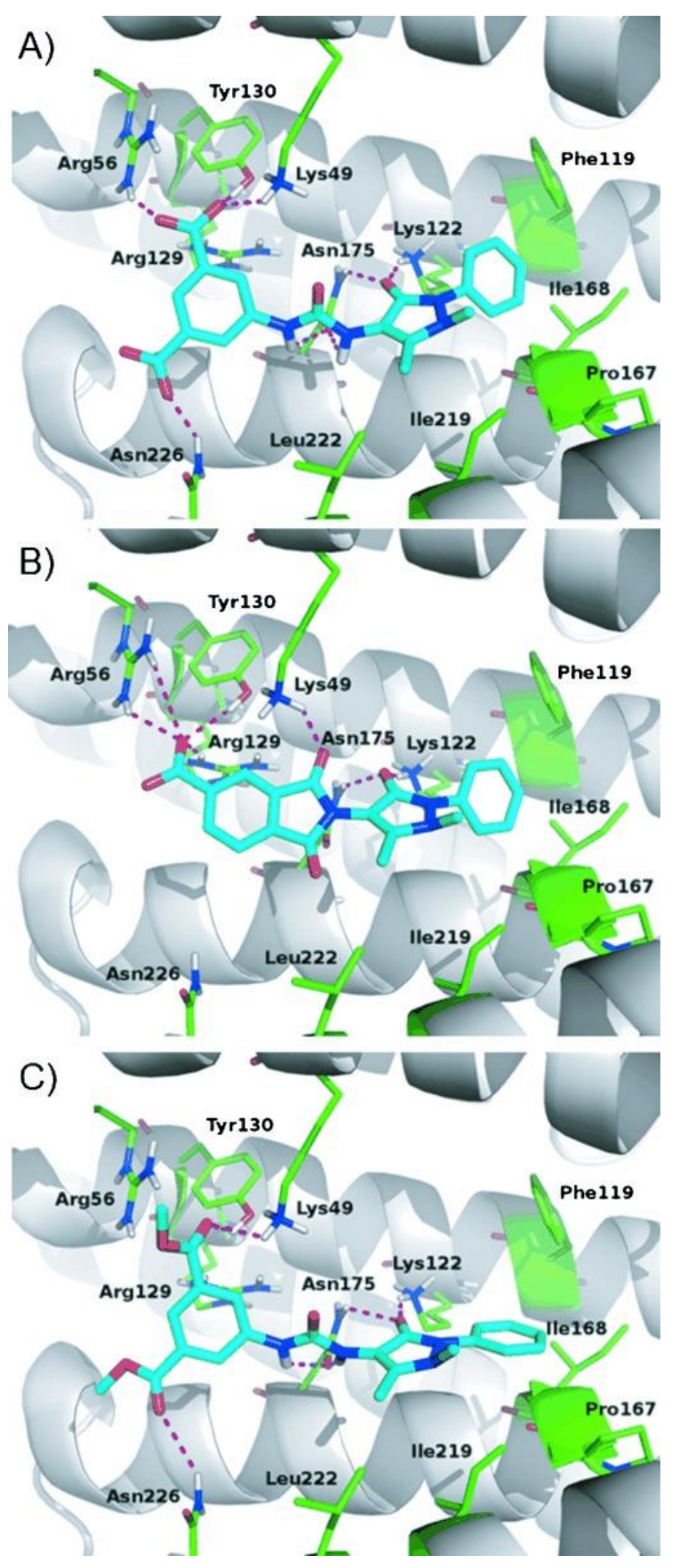


Figure 4

A)

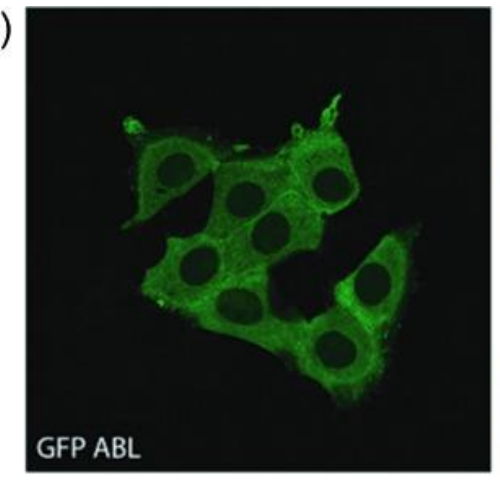

C)

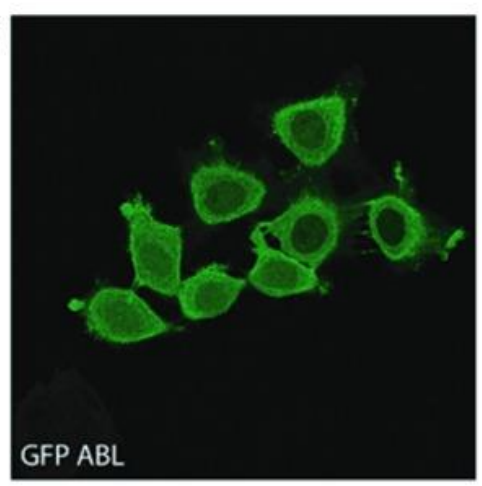

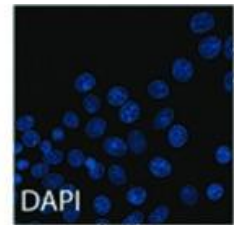

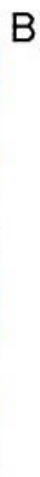

Merge
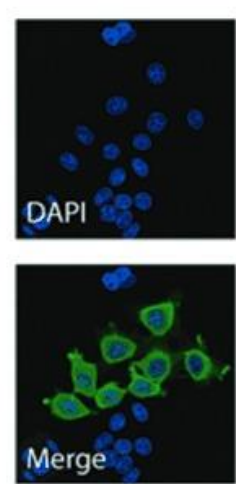

B)

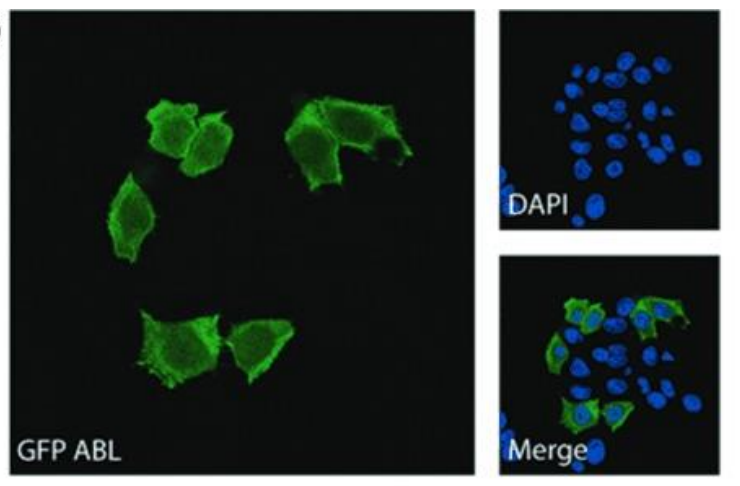

D) $\square$ control ש $9 \square 10$

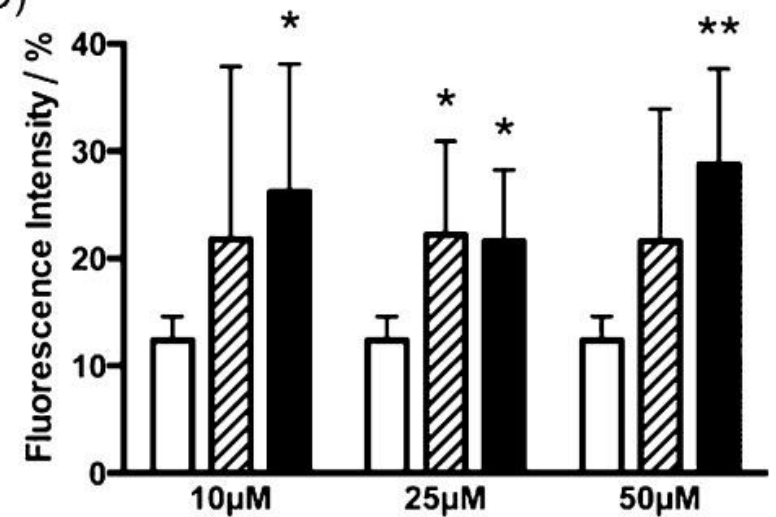


Figure 5
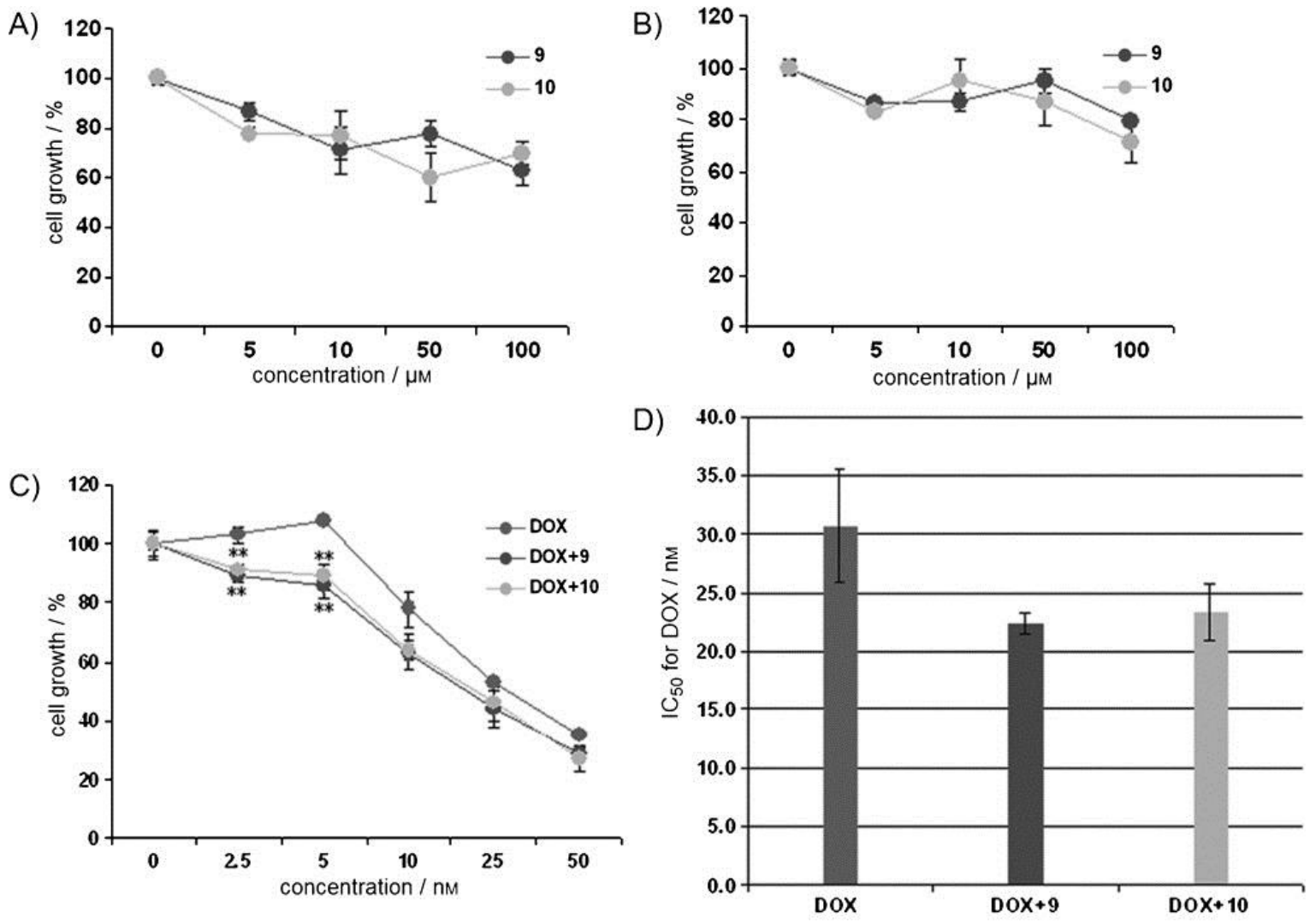

E)
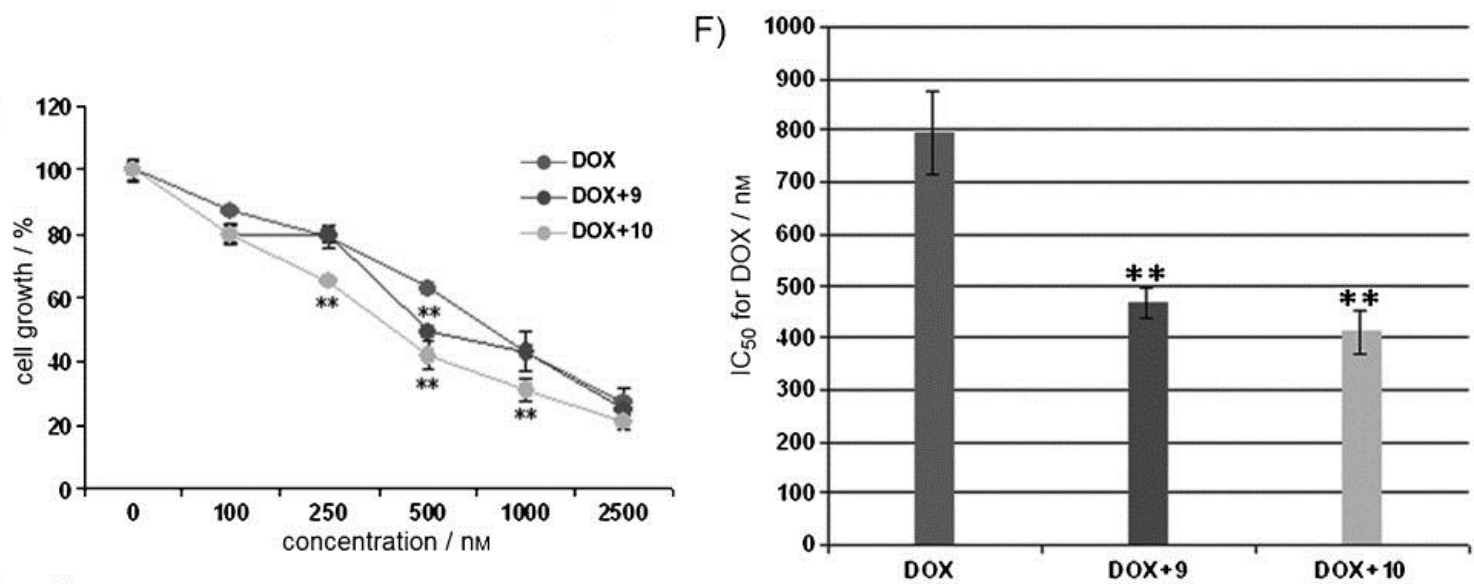

G)

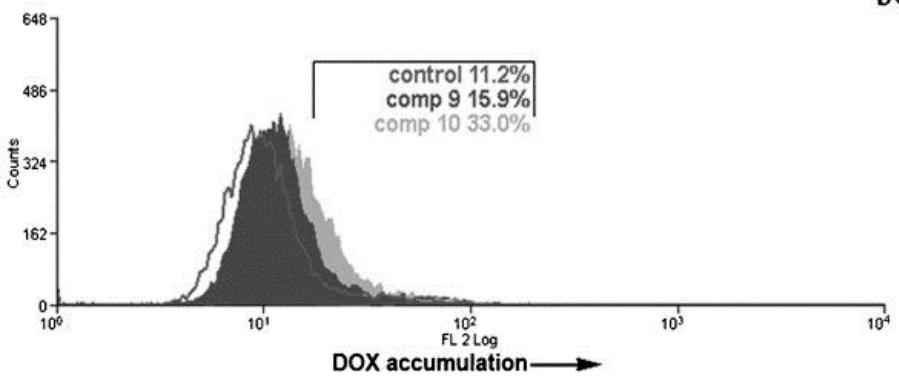


Figure 6
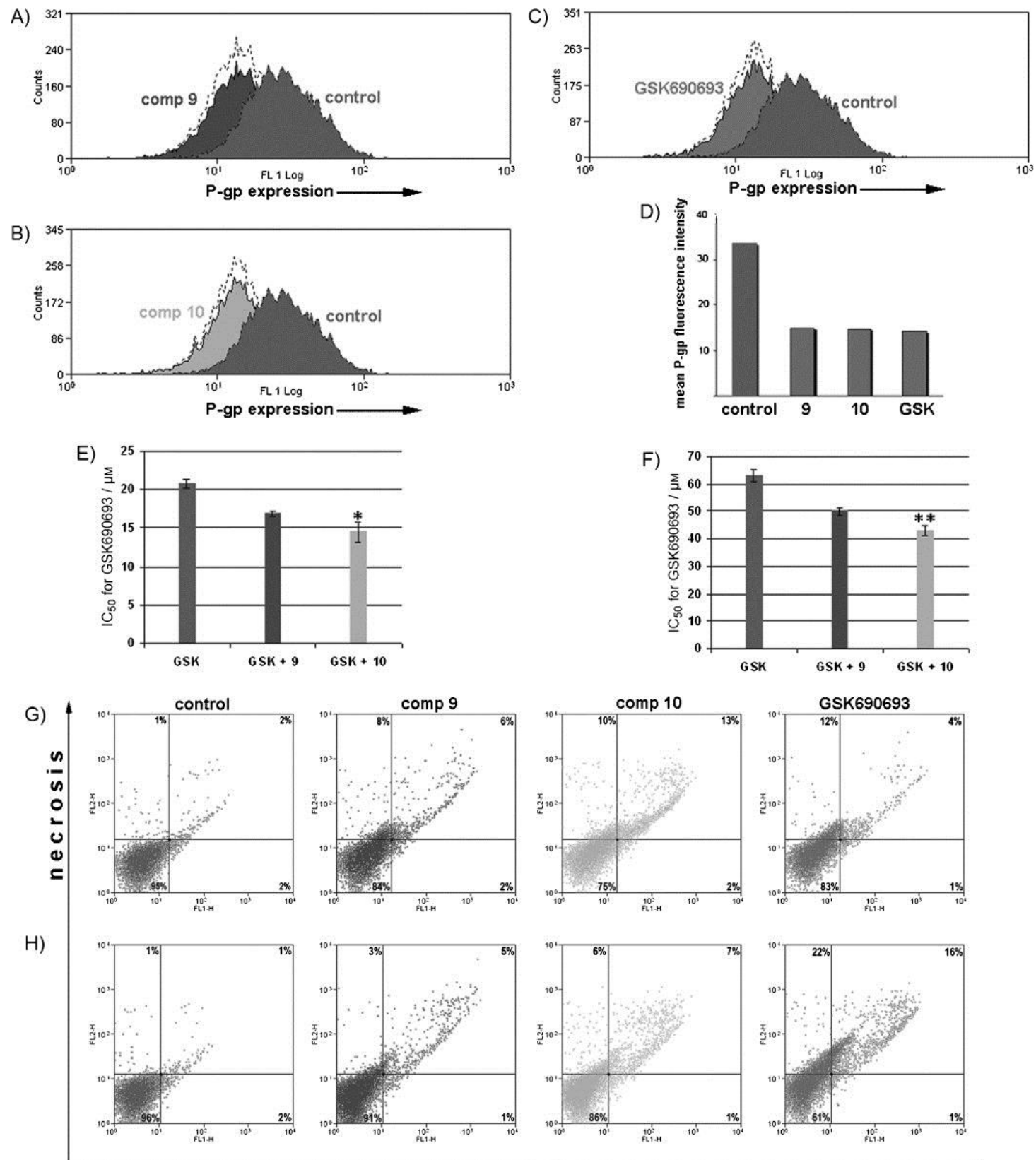

poptosis 